\title{
Eficácia dos Controles de Capitais no Brasil: Uma Abordagem Teórica e Empírica Alternativa
}

\author{
- Guilherme Jonas Costa da Silva* \\ - Marco Flávio da Cunha Resende**
}

\begin{abstract}
Resumo
Este artigo tem por objetivo aprofundar a discussão sobre a eficácia dos controles de capitais no Brasil, no final da década de 1990. Avalia-se a hipótese de que os controles de capitais no Brasil foram endógenos. Em seguida, busca-se testar se controles exógenos são superiores aos endógenos e, mais, se, em momentos de crise cambial, os controles via preços seriam tão eficientes quanto os controles de capitais quantitativos. Para tanto, emprega-se, de modo pioneiro, o método de estimação VAR para testar tais hipóteses. Os resultados observados sugerem que os controles de capitais no Brasil foram de fato endógenos e eficazes em conter uma parte significativa da fuga de capitais no período analisado. A hipótese de que os controles exógenos seriam relativamente melhores não foi rejeitada, embora também não fossem suficientemente eficazes para reverter totalmente a crise cambial de 1999. Com efeito, as evidências permitem inferir que, nos momentos de grande instabilidade financeira, apenas os controles de capitais quantitativos seriam capazes de conter totalmente uma massiva fuga de capital.
\end{abstract}

\section{Palavras-Chave}

vulnerabilidade externa, controles de capitais, economia brasileira

\begin{abstract}
The aim of this paper is to evaluate the effectiveness of capital controls in Brazil, at the end of the 1990s. To do this, we test some hypotheses about capital controls in Brazil. The first hypothesis is that capital controls in Brazil were endogenous during the 1990s. The second one is that exogenous capital controls were more effective than the endogenous one. The third hypothesis is that capital controls by prices have the same effectiveness as quantitative controls when an external crisis is happening. To test these hypotheses the Autoregressive Vector method was used. This method is used in a pioneer way to test hypotheses about capital controls. The results highlight that capital controls in Brazil were endogenous and partially successful to obstruct the capital flight in 1999, although the exogenous controls seem to be more effective than the endogenous one. Another conclusion of the paper is that in periods of large financial instability only the quantitative capital controls are capable to obstruct all the capital flight.
\end{abstract}

\section{Keywords}

external vulnerability, capital controls, Brazilian economy

\section{JEL Classification}

F32, G18, E12

\footnotetext{
* Instituto de Economia, Universidade Federal de Uberlândia (IE-UFU) e Centro de Planejamento e Desenvolvimento Regional da UFMG (CEDEPLAR/UFMG). E-mail: guilhermejonas@ie.ufu.br.

** Centro de Planejamento e Desenvolvimento Regional, UFMG (CEDEPLAR/UFMG) e CNPq. E-mail: resende@cedeplar.ufmg.br.

Endereço para contato: Av. João Naves de Ávila, 2121 - Campus Santa Mônica - Bloco 1J - Sala 1J241 - Bairro Santa Mônica - Uberlândia - MG - Brasil. CEP 38400-902.

(Recebido em março de 2008. Revisões requeridas em março de 2009. Aceito para publicação em dezembro de 2009).
} 


\section{Introdução}

Os controles de capitais podem ser peça importante para uma estratégia de crescimento econômico sustentado, principalmente em economias marcadas pela instabilidade macroeconômica. Tais controles selecionam os fluxos de capital, confinando os capitais especulativos a volumes administráveis e isolando a economia, em algum grau, dos choques externos. Assim, os controles de capitais atuam no sentido de reduzir a volatilidade das taxas de câmbio e de juros, ajudando a estimular as decisões de investimento na economia (CARVALHO; SICSÚ, 2007, cap. 7; PAULA; OREIRO; SILVA, 2003).

Recentemente, observou-se o crescimento e a diversificação dos fluxos financeiros internacionais, acompanhados do aumento da participação de ativos de elevada liquidez na estrutura do passivo externo das economias. O horizonte de curto prazo passou a prevalecer no âmbito dos fluxos internacionais de capital e o humor dos mercados financeiros internacionais tornou-se relevante na determinação de tais fluxos (FFRENCH-DAVIS, 2003).

Se este contexto das finanças internacionais amplia a vulnerabilidade externa das economias, as moedas das economias cujo sistema nacional de inovações (SI) é pouco desenvolvido tornam-se ainda mais vulneráveis às vicissitudes dos mercados financeiros mundiais (RESENDE, 2005; RESENDE; AMADO; 2007; AMADO et al., 2008). A partir do estudo da interação de elementos de cunho Neo-Schumpeteriano com elementos de cunho pós-Keynesiano, estes autores demonstram que os ciclos de crescimento das economias em desenvolvimento são mais afetados pelos ciclos da liquidez internacional vis-à-vis aos ciclos das economias desenvolvidas. O baixo desenvolvimento relativo do SI de uma economia afeta o grau de sua vulnerabilidade externa, com efeitos sobre o posicionamento do sistema financeiro internacional em relação a esta economia e sobre seus ciclos de crescimento.

Sendo assim, no caso das economias com menor desenvolvimento relativo de seus SIs, a política de controle de capitais torna-se ainda mais relevante, visto que estas economias são caracterizadas por elevada vulnerabilidade externa de caráter estrutural. Segundo Albuquerque (1999), são as economias em desenvolvimento aquelas que apresentam pequeno desenvolvimento relativo de seus SIs e, entre estas, encontra-se a economia brasileira. Ademais, autores como Carvalho e Sicsú (2007, cap. 7) e Paula, Oreiro e Silva (2003) argumentam que os controles de capitais já foram adotados com sucesso em diversos países. Portanto, o estudo e aplicação de controle de capitais é pertinente para o caso brasileiro. 
As evidências de controles de capitais, adotados no Brasil na década de 1990, sugerem que estes eram aplicados sobre a entrada e a saída de recursos estrangeiros e feitos por intermédio da cobrança de imposto sobre operações financeiras (IOF). Estudos recentes demonstraram que os controles de capitais feitos sobre a entrada de capitais externos eram endógenos, ou seja, o governo reagia aumentando o controle nos períodos de boom e liberalizando nos períodos de crise. Conforme Schneider (2000), os controles de capitais no Brasil não foram eficientes em conter as pressões contra a moeda doméstica. Entretanto, não há estudos sobre os controles via preços adotados na saída dos capitais externos, se estes foram endógenos ou exógenos e sua eficácia em conter parte dos movimentos de capitais, entre outras coisas, o que justificaria o esforço de reexame da (in)eficácia dos controles de capitais no Brasil.

O presente artigo tem por objetivo aprofundar a discussão sobre a eficácia dos controles de capitais no Brasil, no final da década de 1990. Busca-se, também, avaliar se controles exógenos são superiores aos endógenos e, ainda, se, em momentos de crise cambial, os controles via preços são tão eficientes quanto os controles quantitativos. Para tanto, o trabalho foi estruturado em quatro seções, além desta introdução. Na segunda seção, define-se o comportamento do sistema financeiro internacional, baseando-se na abordagem Minskyana de instabilidade financeira, com intuito de entender os motivos para a maior volatilidade dos fluxos de capitais nas economias em desenvolvimento (cujo SI é relativamente menos desenvolvido) vis-à-vis às economias desenvolvidas. Na seção seguinte, discute-se a teoria dos controles de capitais, os tipos, os objetivos e seus possíveis desdobramentos para a economia brasileira; na quarta seção, a metodologia econométrica e as evidências empíricas são apresentadas. Na última seção - a título de conclusão -, resgatam-se os principais resultados encontrados no artigo.

\section{Sistema Nacional de Inovação, Fluxos de Capitais e os Ciclos das Econo- mias em Desenvolvimento}

Nas últimas décadas, observou-se o crescimento e a diversificação dos fluxos financeiros internacionais. Este fenômeno vem acompanhado pela substituição do crédito bancário de longo prazo por fluxos de investimento de portfólio, financiamento bancário de médio e curto termo e fluxos de capitais ligados a fusões e aquisições. Isto resultou no aumento da participação de ativos de elevada liquidez na estrutura do passivo externo das economias (FFRENCH-DAVIS, 2003).

Deste modo, os fluxos financeiros nos últimos anos tornaram-se bem mais voláteis vis-à-vis aos fluxos de períodos anteriores. Os agentes predominantes no mercado 
financeiro especializaram-se em investimentos de alta liquidez, tornando-se mais responsivos a mudanças nas variáveis que afetam os retornos de curto prazo. O horizonte de curto prazo passou a prevalecer no âmbito dos fluxos internacionais de capital e o humor dos mercados financeiros internacionais tornou-se relevante na determinação de tais fluxos (FFRENCH-DAVIS, 2003; FFRENCH-DAVIS; OCAMPO, 2001; PLIHON, 1995).

Segundo Resende e Amado (2007), esta volatilidade dos fluxos de capitais é amplificada pelo comportamento Minskyano do sistema financeiro internacional em um contexto de incerteza e de ausência de instituições coordenadoras e flexibilizadoras da oferta de liquidez em nível mundial. Mais ainda, tal comportamento do sistema financeiro internacional implica maior volatilidade dos fluxos de capitais nas economias em desenvolvimento vis-à-vis às economias desenvolvidas. Este fenômeno pode ser explicado por meio da interação de elementos de cunho Schumpeteriano com elementos de cunho pós-Keynesiano, que produz especificidades no vínculo das economias em desenvolvimento com os mercados financeiros mundiais, conforme se argumenta a seguir.

O conceito de Sistema Nacional de Inovações (doravante SI) está elaborado na literatura neo-Schumpeteriana. ${ }^{1}$ Nelson (2005), Freeman (2004), Fagerberg (1994), Dosi et al. (1994), entre outros, ressaltam os efeitos positivos do SI sobre a produtividade e a competitividade de uma economia, considerando, inclusive, a impossibilidade de substituição do SI pela importação de tecnologias, visto que a tecnologia tem um caráter local. Assim, a despeito do processo recente de globalização, o SI permanece fundamental para o desenvolvimento do progresso técnico e sua difusão (FREEMAN, 2004). Com respeito à relação entre SI e a competitividade de uma economia, Freeman (2004, p. 25, apud PORTER, 1990) argumenta que:

A vantagem competitiva é criada e sustentada através de um processo altamente localizado. Diferenças em estruturas econômicas nacionais, valores, culturas, instituições e histórias, contribuem profundamente para o sucesso competitivo. O papel da nação parece ser tão forte quanto ou mais forte do que nunca. Enquanto a globalização da competição pode fazer parecer o papel da nação

1 "Trata-se de uma construção institucional que impulsiona o progresso tecnológico (...) através da construção de um sistema nacional de inovações, viabiliza-se a realização de fluxos de informação e conhecimento científico e tecnológico necessários ao processo de inovação. Esses arranjos institucionais envolvem firmas, redes de interação entre empresas, agências governamentais, universidades, institutos de pesquisa e laboratório de empresas, bem como a atividade de cientistas e engenheiros: arranjos institucionais que se articulam com o sistema educacional, com o setor industrial e empresarial e com as instituições financeiras, compondo o circuito dos agentes que são responsáveis pela geração, implementação e difusão das inovações tecnológicas." (ALBUQUERQUE, 1996. p. 228). 
menos importante, ao contrário, ele torna-se ainda mais importante. Com poucas barreiras ao comércio para proteger firmas e indústrias domésticas não competitivas, a nação ganha crescente importância porque ela é a fonte de habilidades e de tecnologia que leva à vantagem competitiva.

Fajnzylber (1983), estudando a competitividade das economias periféricas (em desenvolvimento) no contexto da relação Centro x Periferia desenvolvida em estudos da Comissão Econômica para a América Latina (CEPAL), aproximou-se da Escola neo-Schumpeteriana e de seu conceito de SI. Segundo este autor, uma indústria desprovida de um "núcleo endógeno de dinamização tecnológica" não permitiria a superação da vulnerabilidade externa das economias periféricas. Por núcleo endógeno de dinamização tecnológica ele entende uma infraestrutura científico-tecnológica estreitamente inserida e vinculada ao aparato produtivo, nos moldes propostos pelos neo-Schumpeterianos para o SI. ${ }^{2}$

Segundo os neo-Schumpeterianos, o progresso tecnológico e seus efeitos positivos sobre a produtividade e a competitividade da economia são espacialmente localizados (FAGERBERG, 1994, p. 1156-1161). Portanto, quanto menos desenvolvido for o SI de uma economia, menor será o progresso técnico desta e, então, menor será sua competitividade (FREEMAN, 2004; FAGERBERG, 1994; DOSI et al., 1994; BERNARDES; ALBUQUERQUE, 2003). Menor será, também, sua capacidade de produzir bens que estão na fronteira tecnológica ou próximos a ela. Assim, menor tende a ser a diversificação da estrutura produtiva da economia e maior tende a ser seu coeficiente de importação em relação ao seu coeficiente de exportação, principalmente nas fases ascendentes dos ciclos de crescimento econômico.

A relação entre desenvolvimento do SI, ganhos de competitividade e redução da vulnerabilidade externa da economia foi estudada em Resende e Torres (2008) e em Amado et al. (2008). Estes autores demonstraram que, no país onde o SI é relativamente menos desenvolvido, a despeito de sua industrialização, sua elasticidade-renda da demanda de exportação tende a ser inferior à sua elasticidade-renda da demanda de importação, ensejando uma vulnerabilidade externa estrutural, nos moldes propostos por autores da Cepal, como Prebisch (2000), e de cunho Kaldoriano, como McCombie e Thirwall (1994). A vulnerabilidade externa estrutural das economias em desenvolvimento, que decorre do menor desenvolvimento

2 Ou seja, na sua constituição, participaria "uma ampla gama de agentes e motivações: plantas industriais, institutos de tecnologia, institutos de ciência básica, organismos que preparam pessoal qualificado dos distintos níveis e os ministérios e órgãos centrais que definem políticas e normas; é na interação entre esses agentes e motivações que se dá o processo de criatividade (...) associado ao processo de aprendizagem, que é fator determinante da competitividade a longo prazo." (FAJNZYLBER, 1983, p. 281). 
de seus SIs em relação aos SIs das economias desenvolvidas, produz efeitos distintos sobre o comportamento do sistema financeiro internacional em relação ao grupo das economias desenvolvidas e ao grupo das economias em desenvolvimento.

A relação entre a vulnerabilidade externa estrutural de uma economia e o sistema financeiro internacional é compatível com o paradigma pós-Keynesiano e pode ser estudada por meio deste. A abordagem Minskyana de instabilidade financeira e seus reflexos sobre a economia real têm sido resgatados recentemente para explicar as crises cambiais por que têm passado as economias ditas em desenvolvimento.

Embora as análises de Minsky (1986) estejam associadas a economias fechadas, recentes trabalhos têm procurado fazer o mesmo tipo de análise para crises cambiais em diversas economias, sobretudo economias em desenvolvimento (PAULA; ALVES JR., 2000; ARESTIS; GLICKMAN, 2002; RESENDE, 2005; RESENDE; AMADO, 2007). Estes trabalhos tendem a tratar o sistema financeiro internacional nos moldes dos desenvolvimentos de Minsky (1986) e tratam os países como unidades econômicas (hedge, especulativa ou ponzi), que estão próximas à categorização sobre vulnerabilidade desenvolvida por aquele autor. Estabelecem, assim, medidas para a vulnerabilidade e procuram mostrar como, através do ciclo recente dessas economias, chega-se à crise cambial.

Dow (1993, p. 171-176) demonstrou a natureza específica da relação das economias em desenvolvimento com o sistema financeiro internacional. Este exerce um controle discricionário no que diz respeito à distribuição e ao volume de crédito externo, em um contexto de incerteza. ${ }^{3}$ Quanto maior a incerteza sobre a capacidade dos devedores em honrar seus compromissos, maior será a preferência pela liquidez do sistema financeiro. Mesmo supondo que o crédito internacional seja perfeitamente endógeno, as economias cuja possibilidade de default é alta (incerto) sofrerão racionamento de crédito externo.

Segundo Resende (2005), economias classificadas na categoria especulativa/ponzi pelos mercados financeiros mundiais seriam aquelas com menor capacidade relativa em gerar o influxo líquido de divisas externas necessário (seja pela balança comercial, de serviços ou de capitais) para honrar seus compromissos financeiros internacionais. Assim, as economias cujo SI possui baixo desenvolvimento relativo são menos competitivas e apresentam menor capacidade relativa de gerar os recursos necessários para honrar seus compromissos financeiros internacionais. Consequentemente, tais economias apresentam elevada vulnerabilidade externa e são classificadas pelo sistema financeiro internacional como unidades espe-

3 O conceito de incerteza está definido na literatura pós-Keynesiana e difere do conceito de risco. Ver, por exemplo, Dow (1985, p. 184-203) e Carvalho (1992, p. 54-69). 
culativas ou ponzi. De outro lado, Albuquerque (1999) demonstrou que as economias com menor desenvolvimento relativo de seus SI's são as economias em desenvolvimento.

O sistema financeiro internacional, por seu turno, se comportaria conforme esquema semelhante ao proposto por Minsky (1986). Em função do aumento cíclico da liquidez internacional, em grande parte endogenamente gerada através de inovações financeiras, os mercados financeiros externos aceitam financiar países com características de unidade especulativa e mesmo ponzi. Ou seja, nos períodos de ascensão cíclica da liquidez mundial, o otimismo que prevalece nos mercados externos estimula o finance internacional e a captação de recursos, inclusive pelas economias de caráter especulativo/ponzi. Os resultados positivos de seus balanços de pagamentos denotam ampliação da oferta de finance e amenizam a incerteza quanto à disponibilidade futura de divisas externas, mitigando aumentos na preferência pela liquidez. Deste modo, ao mesmo tempo em que desequilíbrios em transações correntes podem acumular-se como contrapartida de superávits na conta financeira do balanço de pagamentos, a redução temporária da preferência pela liquidez (e da escassez de moeda externa) viabiliza o aumento dos investimentos e o crescimento econômico nos países especulativos/ponzi. ${ }^{4}$

Todavia, nos períodos de reversão cíclica do nível da liquidez mundial, o sistema financeiro internacional teria um comportamento assimétrico: o racionamento de crédito seria mais intenso para as economias especulativas/ponzi vis-à-vis às economias hedge, aguçando, ao invés de contornar, a tendência à escassez de divisas externas daquelas economias. A crise cambial que então se instala nessas economias, muitas vezes amplificada pela sua abertura financeira, alimenta as expectativas quanto à desvalorização de suas taxas de câmbio e, assim, o decorrente aumento da preferência pela liquidez é satisfeito através da demanda por moeda externa, provocando fuga de capitais. ${ }^{5}$

Nestes termos, a redução da vulnerabilidade externa estrutural torna-se parte fundamental numa estratégia de crescimento sustentado de uma economia. Resende e Amado (2007) e Amado et al. (2008) consideram que os ciclos de crescimento das economias em desenvolvimento se verificam de modo reflexo aos ciclos da liquidez internacional. Estes autores demonstram que os ciclos de crescimento das economias em desenvolvimento são mais aderentes aos ciclos do sistema financeiro

4 O crescimento econômico é viabilizado, inclusive, pelo afastamento da restrição de divisas externas. Tal restrição está relacionada à Lei de Thirlwall. Sobre a Lei de Thirlwall e a experiência brasileira, ver Jayme Jr. (2003).

5 Conforme Dow (1999, p. 154-155): “(..) na economia internacional há uma gama de moedas (...) suponha que, para um dado grau de preferência pela liquidez, ocorra uma perda de confiança na estabilidade do valor da moeda doméstica relativamente às outras moedas, então as moedas estrangeiras irão satisfazer melhor aquela preferência pela liquidez". 
internacional, em relação aos ciclos das economias desenvolvidas. Mais ainda, tais resultados reforçam a tese de que os fluxos financeiros são mais instáveis e voláteis nas economias em desenvolvimento vis-à-vis às demais economias, o que constitui um argumento favorável à adoção de controles de capitais naquela categoria de países. A proposta de adoção dos controles de capitais, sugerida neste artigo, se deve ao fato de que as economias em desenvolvimento não possuem duas das principais condições necessárias para se beneficiar da conversibilidade plena da conta de capitais, quais sejam, um SI maduro e um sistema financeiro doméstico desenvolvido o suficiente para absorver um fluxo excessivo de capitais.

\section{Controles de Capitais: Teoria e Evidência}

A instabilidade crônica do mercado financeiro internacional e seus desdobramentos para as economias em desenvolvimento favorecem a recorrência de crises cambiais nessas economias, classificadas no sistema financeiro internacional como unidades especulativas e ponzi. Assim, deve-se pensar uma estratégia complementar que reduza a vulnerabilidade externa das mesmas. Estudos recentes sugerem a adoção de medidas restritivas sobre os fluxos de capitais como uma alternativa viável para esse propósito (CARVALHO; SICSÚ, 2007; OREIRO; PAULA; SILVA, 2004).

As medidas restritivas sobre o fluxo de capitais podem ser utilizadas como instrumentos temporários ou permanentes e divididos em seletivos ou extensivos. Os controles de capitais seletivos cobrem determinadas modalidades de operações financeiras relacionadas a fluxos externos. Os controles extensivos são mais abrangentes, cobrem todas as operações financeiras. Os controles utilizados como instrumentos temporários servem como instrumentos transitórios no contexto de um processo gradual de liberalização financeira ou de incertezas no mercado internacional, até que o ambiente torne-se mais propício para a integração da economia com o mercado mundial. Os controles utilizados como instrumentos permanentes são usados para garantir uma maior estabilidade econômica e financeira ao país.

Os controles de capitais podem ser classificados ainda em controles administrativos (quantitativos) e controles de mercado (baseados em preços). Os controles de capitais diretos ou administrativos restringem determinadas transações financeiras e transferência de fundos através da completa proibição ou limites quantitativos explícitos. Esse tipo de controle impõe proibições ou limites para a atuação de investidores. Por exemplo, um país pode proibir que investidores estrangeiros apliquem recursos na sua bolsa de valores. Portanto, os controles administrativos procuram afetar diretamente o volume de determinadas transações financeiras. Os controles de capitais indiretos ou de mercado (baseados em preços) desencorajam o 
movimento de capital e as transações associadas, tornando-as mais onerosas. Esses controles funcionam via desestímulo aos fluxos de capitais, impondo custos para determinados tipos de operação financeira. Assim, um governo pode cobrar uma taxa de investidores estrangeiros que queiram aplicar na bolsa de valores. Segundo Paula (2003), os controles baseados em preços podem ser diferenciados de modo a desestimular certos tipos de transação ou maturidades.

As medidas restritivas impostas sobre o fluxo de capitais são implementadas tanto na sua entrada quanto na sua saída: i) a implementação desses controles na entrada justifica-se pela função preventiva, visando evitar os efeitos indesejáveis do fluxo excessivo de capitais; ii) no caso da implementação das medidas restritivas na saída, o objetivo é onerar a fuga de capitais; tenta-se desvincular a ligação entre as taxas de juros interna e externa. Segundo Neely (1999):

Controls on capital inflows and outflows provide some slack for monetary policy discretion under fixed exchange rates, but in opposite directions. Controls on capital inflows, which allow for higher interest rates, have been used to try to prevent an expansion of the money supply and the accompanying inflation (...) In contrast, controls on capital outflows permit lower interest rates and higher money growth ... They most often have been used to postpone a choice between devaluation or tighter monetary policy, as they have been in Malaysia, for example. (NEELY, 1999, p. 23).

Nesse contexto, acredita-se que a política de controles de capitais pode ser uma das peças fundamentais para garantir o sucesso da estratégia de redução da vulnerabilidade externa estrutural, tendo em vista que seleciona os fluxos de capital que se deseja absorver, priorizando os investimentos produtivos ou de maturidade mais longa, e confinando os capitais especulativos a volumes administráveis, isolando, em algum grau, o país dos choques externos. Assim, os controles de capitais atuariam no sentido de guiar o estado de confiança no país e atenuar a intensidade dos efeitos de uma eventual instabilidade no mercado financeiro internacional, reduzindo a volatilidade da taxa de câmbio e da taxa de juros, o que facilita e estimula as decisões de investimento na economia.

As evidências empíricas da eficácia dos controles de capitais, tal como descrita por Ariyoshi et al. (2000), mostram que a adoção de medidas restritivas confere maior autonomia à política monetária, reduz a vulnerabilidade externa da economia e estabiliza as taxas de câmbio e de juros, garantindo um ambiente mais estável e seguro para os investimentos produtivos. Nas palavras de Ariyoshi et al. (2000): 
The effectiveness of capital controls has frequently been assessed on the basis of their impact on capital flows and policy objectives, such as maintaining exchange rate stability, providing greater monetary policy autonomy, or preserving domestic macroeconomic and financial stability. (ARIYOSHI et al., 2000, p. 5).

Os resultados apresentados pelos países que adotaram os controles de capitais dão suporte a esse argumento. Tais evidências mostram que há uma realocação de capitais de curto prazo em favor dos capitais de longo prazo, dinamizando a economia. Ademais, com a autonomia da política monetária adquirida a partir da adoção dos controles de capitais, o governo poderia reduzir a taxa de juros e garantir um aumento da oferta de crédito a custos menores, favorecendo o crescimento econômico.

As externalidades positivas da liberalização, até meados da década de 1990, eram aceitas pela maioria dos acadêmicos, mas, quando uma sucessão de crises cambiais começou a ocorrer no final da década passada, reacendeu a discussão. Nas palavras de Edwards (2001):

The opening of domestic capital markets to foreigners is, perhaps, the most reviled aspect of this "consensus."... Indeed, a number of academics have argued that the free(er) mobility of private capital during the 1990s was behind the succession of crises that the emerging markets experienced during that decade. According to this view, increased capital mobility inflicts many costs and generates (very) limited benefits to the emerging nations. It has been argued that, since emerging markets lack modern financial institutions, they are particularly vulnerable to the volatility of global financial market. (EDWARDS, 2001, p. 1).

A literatura ainda está longe de chegar a um consenso sobre a correlação entre liberalização da conta de capitais e performance macroeconômica, por diversos fatores, tais como as diferentes metodologias utilizadas para o cálculo da liberalização, o tamanho e a heterogeneidade da amostra. Contudo, a análise empírica internacional demonstrou que os controles sobre o influxo de capitais, adotados pela economia chilena, contribuiram para melhorar a performance macroeconômica do país, na medida em que conseguiram conter a apreciação da taxa de câmbio a ponto de financiar seus déficits em transações correntes fundamentalmente com investimento direto estrangeiro. ${ }^{6}$

6 Mais detalhes, consultar Edwards, Gregório e Valdés (2000) e Ffrench-Davis e Villar (2003). 
Nos anos recentes, as medidas de controles de capital implementadas pelo governo brasileiro caminharam no sentido de ajustar os fluxos de capitais às necessidades impostas pelas expectativas dos agentes e pela conjuntura econômica no mercado mundial. Os controles de capitais no Brasil tomaram a forma de medidas administrativas (mudanças nos prazo médio mínimo de amortização para empréstimos) e medidas baseadas em preços (variações no IOF - Imposto sobre Operações Financeiras), que foram continuamente revisadas para evitar que os participantes do mercado encontrassem maneiras de burlar as medidas restritivas sobre o fluxo de capitais. Todavia, Schneider (2000) afirmou que os controles de capitais no Brasil não foram eficientes em conter as pressões contra a moeda doméstica. Nas palavras do autor:

The experience of Brazil illustrates the ineffectiveness of controls in an environment of pervasive macroeconomic imbalances. A complex mixture of direct and indirect controls was largely ineffective in stemming inflows, shifting their composition towards longer-term flows and providing a greater degree of monetary independence. The inability of the state to reign in large fiscal deficits fuelled expectations of continued inflation and resulted in widening interest rate differentials. These interest differentials combined with a stable exchange rate to induce large inflows of capital. The imposition of direct and indirect capital controls in mid-1993 and their intensification under the Real plan in 1994 had little effect on the rising level of inflows. (SCHNEIDER, 2000, p. 43-44).

Segundo Cardoso e Goldfajn (1998), Soihet (2002), Paula, Oreiro e Silva (2003), entre outros, os controles de capitais adotados no Brasil, na década de 1990, mostram que estes eram essencialmente endógenos, aplicados sobre a entrada de recursos estrangeiros e feitos fundamentalmente por intermédio da cobrança de IOF sobre os ganhos das aplicações financeiras no País. Os controles de capitais eram principalmente baseados em preços, sob a forma de uma taxação direta sobre a entrada de capitais externos. Os controles eram endógenos porque o governo reagia aumentando o controle nos períodos de boom e liberalizando nos períodos de crise. Dessa forma, os fluxos externos de recursos acabavam por determinar o nível dos controles de capitais, ao invés de serem determinados pelo nível dos referidos controles.

Apesar de a análise desses autores estar aparentemente correta, há fortes indícios de que estão incompletas, já que os dados da Receita Federal demonstram que os controles de capitais no Brasil foram aplicados também na saída. Assim, deve-se 
reexaminar a eficácia conjunta das medidas restritivas na entrada e na saída desses recursos externos.

Apesar de alguns autores afirmarem que os controles endógenos não foram eficazes em conter a crise cambial da economia brasileira em 1999, a literatura carece de uma prova empírica da eficácia conjunta dos controles de capitais no Brasil. A próxima seção avaliará empiricamente a hipótese de que os controles de capitais foram endógenos e ineficazes em atenuar os movimentos de capitais de 1999. Em seguida, será testada a hipótese de que os controles exógenos seriam melhores, naquele momento, vis-à-vis aos controles endógenos. A partir dos resultados encontrados, será possível inferir se apenas os controles quantitativos seriam eficazes nos momentos de grande instabilidade no mercado financeiro internacional.

\section{Base de Dados, Metodologia e Resultados}

Esta seção visa, inicialmente, testar a hipótese de que os controles sobre a entrada e a saída de capitais no Brasil foram endógenos nos anos de 1990. Em seguida, pretende-se avaliar a hipótese de que tais controles não foram eficientes em conter os movimentos de capitais e, consequentemente, as pressões contra a moeda doméstica. Por fim, a atenção volta-se para a hipótese de que os controles de capitais exógenos (preventivos) seriam mais eficazes vis-à-vis aos controles endógenos.

Para avaliar a evolução das medidas implementadas sobre o fluxo de capitais ocorridas na economia brasileira ao longo da década de 1990, a maioria dos trabalhos desenvolvidos no País, tal como Soihet (2002), Oreiro, Paula e Silva (2004) e Ono et al. (2005) utilizam o Índice de Controle de Capitais (ICC), elaborado por Cardoso e Goldfajn (1998). O indicador avalia as mudanças mensais ocorridas na legislação que afetam o fluxo de capital por intermédio das alterações ocorridas no controle à entrada de capital.

Apesar de interessante, o indicador desenvolvido por Cardoso e Goldfajn pode induzir ao erro de medida, já que é baseado em número de medidas restritivas, implicando uma perda de sensibilidade das magnitudes das medidas restritivas efetivamente adotadas pelo País. Por isso, optou-se em trabalhar com o Imposto sobre Operações Financeiras (IOF) por fato gerador, mais especificamente sobre as operações cambiais, que é o indicador que melhor se aproxima de uma medida de controles de capitais no Brasil. Neste caso, duas possibilidades se apresentam como alternativa: a primeira seria utilizar a própria alíquota do IOF; a segunda seria utilizar a arrecadação do IOF. Em função da falta de disponibilidade dos dados requeridos para a primeira possibilidade, adotou-se, neste trabalho, a segunda 
opção. A Receita Federal forneceu os dados sobre o valor do IOF arrecadado sobre operações cambiais referentes à entrada e à saída de divisas externas no Balanço de Pagamentos brasileiro. Tais dados têm periodicidade mensal e dizem respeito ao período janeiro de 1995 a dezembro de 1999. Estes dados foram tomados, neste trabalho, como proxy para os controles sobre a entrada e sobre a saída de capitais no Brasil no citado período, respectivamente.

Conforme a Receita Federal, a incidência de IOF sobre operações de câmbio está regulamentada pela Lei $n^{\circ} 8.894$, de 21 de junho de 1994 , art. $5^{\circ}$. O fato gerador do IOF é a entrega de moeda nacional ou estrangeira, ou de documento que a represente, ou sua colocação à disposição do interessado, em montante equivalente à moeda estrangeira ou nacional entregue ou posta à disposição por este (Lei $n^{\circ}$ 5.172/66, art. 63, inciso II). Ocorre o fato gerador e torna-se devido o IOF no ato da liquidação da operação de câmbio. ${ }^{7}$

A alíquota do IOF, incidente sobre operações com câmbio, era de 25\% (Lei n ${ }^{\circ}$ 8.894/94, art. $5^{\circ}$ ). Entretanto, estava prevista a redução da alíquota do IOF para 2\%, nas seguintes operações: i) aplicação em fundo de renda fixa; ii) operação realizada entre instituições financeiras no exterior e bancos autorizados a operar com câmbio, no Brasil (interbancária), e iii) constituição de disponibilidade de curto prazo, no Brasil, de residentes no exterior. Além disso, a alíquota do IOF fica reduzida à zero nas seguintes operações de câmbio: i) efetuadas pela União, Estados, municípios,

7 Configuram-se como hipóteses para o IOF entrada de moedas, as seguintes operações: i) operações de câmbio relativas aos ingressos de receitas de exportações de bens e serviços; ii) operações de câmbio de transferências do exterior, relativas às aplicações em fundos de investimento; iii) operação de compra de moeda estrangeira por instituição autorizada a operar no mercado de câmbio; iv) operações de câmbio relativas a transferências do exterior, inclusive por meio de operações simultâneas, realizadas por investidor estrangeiro, para aplicação nos mercados financeiros e de capitais, na forma regulamentada pelo Conselho Monetário Nacional - CMN, etc. Configuram-se como hipóteses para o IOF saída de moedas, as seguintes operações: i) operações de câmbio destinadas ao pagamento de importação de serviços; ii) operações de câmbio destinadas ao cumprimento de obrigações de administradoras de cartão de crédito ou de bancos comerciais ou múltiplos na qualidade de emissores de cartão de crédito decorrentes de aquisição de bens e serviços do exterior, por seus usuários; iii) operações de câmbio de transferências para o exterior, relativas as aplicações em fundos de investimento; iv) pagamento de bens importados; v) operações de câmbio relativas a transferências para o exterior, inclusive por meio de operações simultâneas, realizadas por investidor estrangeiro, para aplicação nos mercados financeiro e de capitais, na forma regulamentada pelo Conselho Monetário Nacional - CMN: zero, etc. No período de 1995-1999, a regulamentação do IOF era um pouco diferente da atual (Decreto 6.306, de dezembro/07). Até 1997, a regulamentação se dava por meio de resoluções do Conselho Monetário Nacional (A resolução CMN 1.301/87 é o regulamento). A partir de 1997 (O Decreto 2.219/07 é o regulamento), por decreto do Presidente da República. Este último fixava a alíquota em $2 \%$ para as seguintes operações: transferências do exterior para aplicação em fundo de renda fixa; entre bancos no exterior e instituições brasileiras autorizadas a operar câmbio; disponibilidades de curto prazo de residentes no exterior; zero para as demais transferências do exterior. Havia isenção para as operações de compra de bens do exterior e operações dos Entes Federados e Itaipu. Nos demais casos, a alíquota era de $25 \%$. Mais detalhes, consultar site da receita federal: http://www.receita.fazenda.gov.br/Legislacao/Decretos/Ant2001/Ant1999/Dec221997.htm). 
Distrito Federal, suas fundações e autarquias; ii) em que sejam pagadores ou recebedores, no exterior, agências governamentais ou entidades internacionais acreditadas junto ao governo brasileiro; iii) relativas às demais transferências financeiras do exterior e para o exterior, e iv) vinculadas à importação de serviços e à exportação de bens e serviços (Lei $n^{\circ} 8.894 / 94$, art. $5^{\circ}$ ). Por fim, era isenta do IOF a operação de câmbio realizada para pagamento de bens importados (Decreto-Lei no 2.434, de 19 de maio de 1988 , art. $6^{\circ}$, e Lei $n^{\circ} 8.402 / 92$, art. $1^{\circ}$, inciso XIII) e, também, em que o comprador ou o vendedor da moeda estrangeira seja a Itaipu Binacional e, ainda, operação realizada pelos executores do gasoduto Brasil/Bolívia, inclusive pelas empresas especialmente por eles selecionadas para esse fim, obedecidas as condições previstas no Decreto $\mathrm{n}^{\circ} 2.142$, de 5 de fevereiro de 1997, que promulgou o acordo entre os governos da República Federativa do Brasil e da República da Bolívia.

Portanto, grande parcela da incidência do IOF sobre operações cambiais, relativa ao período abordado neste estudo, se dá sobre a Conta Financeira do Balanço de Pagamentos. Note que, para a balança comercial, por exemplo, a alíquota do IOF era $0 \%$ ou havia isenção do mesmo, enquanto tal alíquota era $0 \%$ para operações efetuadas pela União, Estados, municípios, Distrito Federal, suas fundações e autarquias, etc. Neste estudo, os fluxos de capitais analisados correspondem à seguinte rubrica da Conta Financeira do Balanço de Pagamentos: investimento em carteira (portfólio). Deste modo, constata-se que parcela relevante da incidência do IOF sobre operações cambiais se dá sobre os fluxos de capitais que são objeto de análise neste trabalho, o que credencia a arrecadação do IOF sobre operações com câmbio para ser usada como proxy da variável controle de capitais, no Brasil no período 1995-1999. A proxy nunca é perfeita, isto é, a proxy perfeita de uma variável é ela própria. Deste modo, o uso de proxies só é indicado na ausência da própria variável em estudo. Este é o caso da arrecadação do IOF como proxy para controles de capitais no Brasil, nos anos de 1990. Contudo, visto que a proxy é uma substituta imperfeita da variável com a qual se deseja trabalhar, seu uso requer cautela na análise dos resultados e nas conclusões do estudo.

Para os exercícios econométricos realizados, utilizaram-se as seguintes variáveis: Fluxo de Capitais de Curto Prazo (KCP), Taxa Básica de Juros (TXSELIC), Taxa de Câmbio comercial para compra: real R / dólar americano (U\$) - média (TXCÄMBIO) e Arrecadação do IOF sobre operações cambiais referentes à entrada de divisas (IOFINF) e sobre as operações cambiais referentes à saída de divisas (IOFOUTF), (Figura 1). As primeiras variáveis foram extraídas do Ipeadata e as duas últimas fornecidas pela Receita Federal. 

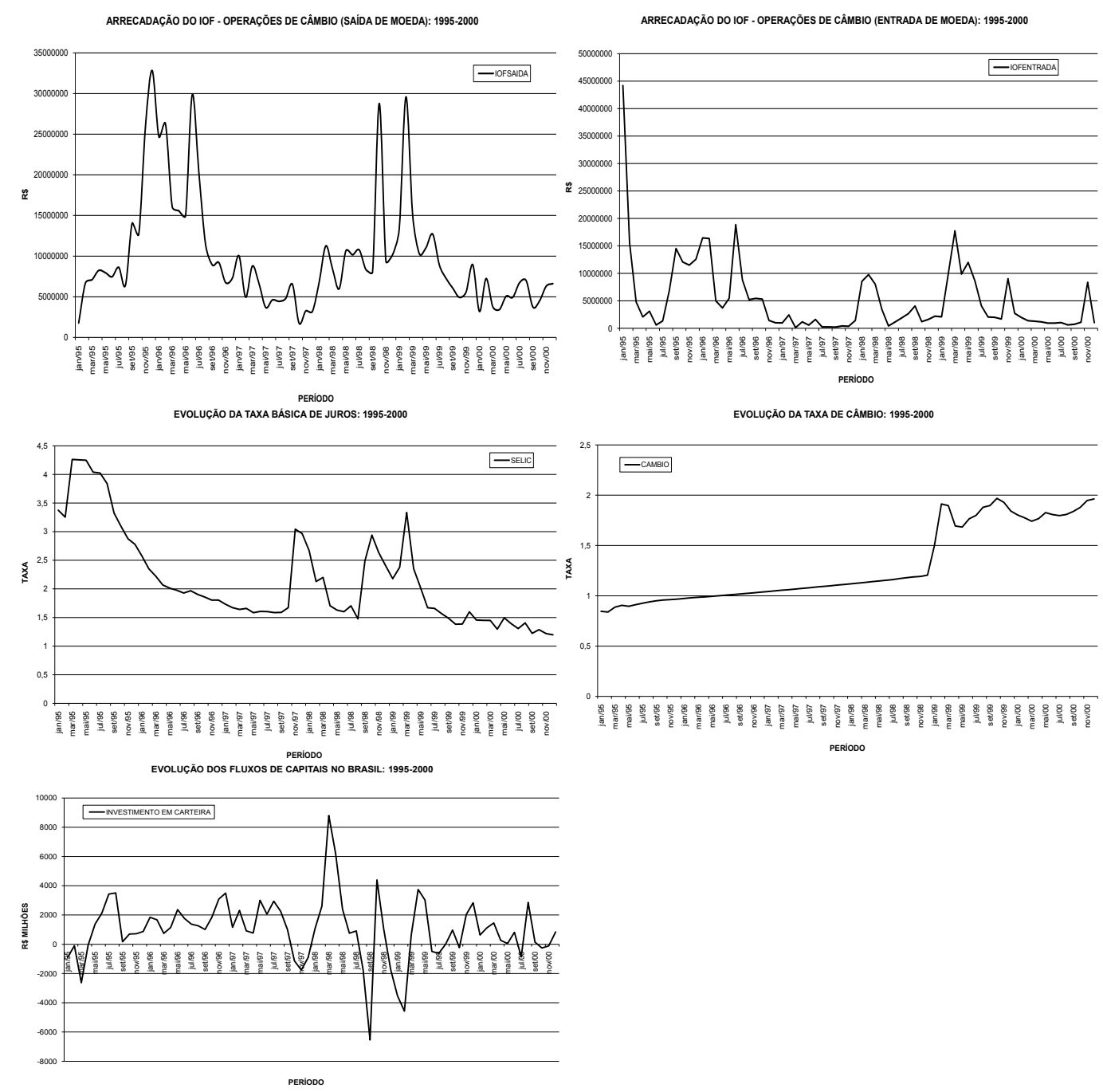

Fonte: Elaboração própria a partir dos dados do Ipeadata e Receita Federal.

Figura 1 - As Variáveis Macroeconômicas em Nível

Como as variáveis em consideração dependem uma das outras, neste trabalho adotou-se o método de estimação de Vetores Autorregressivos (VAR), ${ }^{8}$ como uma metodologia alternativa para avaliar a (in)eficácia dos controles de capitais no Brasil. Nesse caso, cada variável é definida como sendo função de seus próprios valores defasados e das defasagens das demais variáveis consideradas na análise. Com intuito de evitar arbitrariedade na ordenação das variáveis, utilizou-se o Teste de

8 Para mais detalhes da metodologia VAR, consultar Sims (1980) e Enders (1995). 
Causalidade de Granger para definir esse ordenamento de uma forma estatisticamente consistente.

A hipótese básica do modelo, segundo Sims (1980), é que as séries são estacionárias; porém, nem sempre as séries são estacionárias. Assim, para decidir a melhor especificação de um modelo desse tipo, devem-se observar dois aspectos, a saber: a perda da eficiência e a perda de informação. As possibilidades que se apresentam como solução para o problema são as seguintes: ${ }^{9}$ i) estimar todas as variáveis em nível, mesmo na presença de raiz unitária, já que o objetivo do VAR é determinar as relações existentes entre as variáveis e não os parâmetros estimados - o problema é que esta opção implica perda de eficiência na estimação; ii) diferenciar as séries, mas o ganho de eficiência na estimação se dá em detrimento da perda de informações quanto às relações de longo prazo entre as séries; iii) estimar o modelo com Vetor de Correção de Erros (VEC) quando há evidências concretas de relações de cointegração entre as variáveis. Com esta especificação, ganha-se eficiência na estimação sem perder as importantes relações de longo prazo.

Portanto, para a aplicação empírica, inicialmente verificou-se a ordem de integração das séries econômicas por meio dos seguintes testes de estacionariedade: DickeyFuller Aumentado (ADF); Kwiatkowski, Phillips, Schmidt e Shin (1992), ou KPSS, e Dickey-Fuller GLS ou DF-GLS. Enquanto a hipótese nula do teste KPSS é a de que a série é estacionária, nos testes ADF e DF-GLS, a hipótese nula é de que a série testada possui raiz unitária. O intuito de empregar testes com hipóteses nulas opostas é demonstrar o fato de que os testes de raiz unitária têm baixo poder de explicação, o que reduz o grau de confiabilidade dos mesmos (MADDALA; KIM, 1998). De acordo com o teste KPSS, as séries TXCÂMBIO, IOFINF e TXSELIC são I(l) - Tabela 1. O teste DF-GLS sugere que todas as séries são I(1), com exceção da série de KCP (Tabela 2), enquanto o teste ADF indica que as séries de TXCÂMBIO e TXSELIC são I(1) e as séries de KCP, IOFINF e IOFOUT são estacionárias em nível (Tabela 3). ${ }^{10}$ Assim, considera-se que apenas a série da variável KCP é estacionária, pois a hipótese de que tal série possui raiz unitária foi rejeitada em todos os testes realizados. Portanto, a maioria das séries apresenta raiz unitária. Segundo Campbell e Perron (1991), se pelo menos metade das séries apresentarem raiz unitária e havendo pelo menos um vetor cointegrante, pode-se obter estimadores consistentes e eficientes por meio do método de VEC.

9 Mais detalhes, em Ramaswamy e Sløk (1998) e Matsumoto (2000).

10 Mais detalhes dos testes podem ser obtidos em Hamilton (1994, cap. 17). 
Tabela 1 - Teste de Estacionariedade Kwiatkowski-Phillips-Schmidt-Shin (KPSS)

\begin{tabular}{lcccc}
\hline Variável & Constante & Tendência & Estatística LM & Valor Crítico: $5 \%$ \\
\hline KCP & Sim & Não & 0.106972 & 0.4630 \\
TXCAMBIO & Sim & Sim & $\mathbf{0 . 2 1 6 2 3 6 *}$ & 0.1460 \\
IOFINF & Sim & Sim & $\mathbf{0 . 1 5 7 3 1 6 ^ { * }}$ & 0.1460 \\
IOFOUT & Sim & Não & 0.128910 & 0.4630 \\
TXSELIC & Sim & Sim & $\mathbf{0 . 1 7 6 6 5 9 ^ { * }}$ & 0.1460 \\
\hline
\end{tabular}

Fonte: Elaboração própria a partir da saída do Eviews 4.1.

Notas: Para seleção da defasagem, foi utilizado o critério de Newey-West using Bartlett kernel. *Significativo a 5\%. H0: série estacionária; Hl: série não estacionária.

Tabela 2 - Teste de Estacionariedade de Dickey-Fuller GLS (DF-GLS)

\begin{tabular}{lccccc}
\hline Variável & Defasagem & Estatística $t$ & Valor Critico 1\% & Valor Critico 5\% & Valor Critico 10\% \\
\hline KCP & 0 & $-6.301863^{*}$ & -3.735800 & -3.161200 & -2.863000 \\
TXCAMBIO & 3 & -1.575839 & -3.747200 & -3.170800 & -2.872000 \\
IOFINF & 0 & -2.322251 & -3.735800 & -3.161200 & -2.863000 \\
IOFOUT & 0 & -3.476256 & -3.735800 & -3.161200 & -2.863000 \\
TXSELIC & 0 & -2.174627 & -3.735800 & -3.161200 & -2.863000 \\
\hline
\end{tabular}

Fonte: Elaboração própria a partir da saída do Eviews 4.1.

Notas: Para seleção da defasagem, foi utilizado o critério de Newey-West using Bartlett kernel. *Significativo a $1 \%$. Hipótese Nula: raiz unitária (série não estacionária).

Tabela 3 - Teste de Estacionariedade de Dickey-Fuller Aumentado

\begin{tabular}{lccccc}
\hline Discriminação & Defasagem & Constante & Tendência & Estatística $t$ & Valor Critico 1\% \\
\hline $\boldsymbol{K C P}$ & 0 & Sim & Não & $-6.293686^{*}$ & -3.546099 \\
$D K C P$ & 2 & Não & Não & $-7.865227^{\star}$ & -2.606911 \\
$\boldsymbol{T X C A M B I O}$ & 2 & Não & Não & -2.199927 & -2.606163 \\
$D T X C A M B I O$ & 2 & Não & Não & $-3.716265^{*}$ & -2.606911 \\
IOFINF & 0 & Sim & Não & $-7.430031^{*}$ & -3.546099 \\
DIOFINF & 0 & Não & Não & $-8.549039^{*}$ & -2.605442 \\
IOFOUT & 0 & Sim & Não & $-3.797789^{*}$ & -3.546099 \\
DIOFOUT & 2 & Não & Não & $-6.842476^{*}$ & -2.606911 \\
$\boldsymbol{T X S E L I C}$ & 0 & Não & Não & -1.213128 & -2.604746 \\
$D T X S E L I C$ & 0 & Não & Não & $-7.241440^{*}$ & -2.605442 \\
\hline
\end{tabular}

Fonte: Elaboração própria a partir da saída do Eviews 4.1.

Notas: Para seleção da defasagem, foi utilizado o critério de informação de Schwarz (SC). A letra $\mathrm{D}$ refere-se à primeira diferença da variável. *Significativo a $1 \%$. Hipótese Nula: raiz unitária (série não estacionária). 
Visando a melhor especificação do modelo, buscou-se a escolha adequada do número de defasagens para realizar as estimações. Para tanto, tomou-se como base o teste LM de autocorrelação serial e os Critérios de Informação de Akaike (AIC), Schwarz (SC) e Hannan-Quinn (HQ). Conforme a Tabela 4, os testes sugerem a adoção de uma defasagem. Após verificar a ordem de integração das variáveis, realizou-se o teste de cointegração de Johansen. Contudo, a estimação do modelo VAR, onde são contempladas as variáveis KCP, TXCÂMBIO, TXSELIC, IOFINF e IOFOUT, não foi possível em função da presença de matriz singular. Este problema é solucionado quando se elimina do modelo a variável TXCÂMBIO. Deste modo, optou-se por eliminar esta variável do VAR. A estatística do traço $\left(L R_{\text {trace }}\right)$ apontou a presença de pelo menos um vetor de cointegração ao nível de 5\% (Tabela 5).

Tabela 4 - Critério de Seleção da Ordem de Defasagem do Modelo

\begin{tabular}{cccc}
\hline Defasagem & AIC & SC & HQ \\
\hline 0 & 89.21055 & 89.35654 & 89.26701 \\
1 & $86.76288^{*}$ & $87.49282^{\star}$ & $87.04516^{*}$ \\
2 & 86.92065 & 88.23454 & 87.42874 \\
3 & 87.23269 & 89.13054 & 87.96660 \\
4 & 87.62235 & 90.10414 & 88.58208 \\
\hline
\end{tabular}

Fonte: Elaboração própria a partir da saída do Eviews 4.1.

Obs: AIC: Akaike information criterion; SC: Schwarz information criterion, e HQ: Hannan-Quinn information criterion.

Tabela 5 - Sumário do Teste de Cointegração de JOHANSEN e Valores para $L R_{\text {trace }}$

\begin{tabular}{llcccc}
\hline Data Trend: & None & None & Linear & Linear & Quadratic \\
\hline Rank or & No Intercept & Intercept & Intercept & Intercept & Intercept \\
№ of CEs & No Trend & No Trend & No Trend & Trend & Trend \\
Trace & 2 & 2 & 2 & 1 & 2 \\
\hline
\end{tabular}

Fonte: Elaboração própria a partir da saída do Eviews 4.1. Selected (5\% level) Number of Cointegrating Relations by Model (columns).

Obs.: Amostra: 1995:01 1999:12. Included observations: 57. Series: IOFINF IOFOUTF KCP TXSELIC. Lags interval: 1 to 2.

Do exposto, deve-se estimar um modelo VAR, incluindo um vetor de cointegração, para corrigir esses desequilíbrios de curto prazo. Segundo Mendonça (2005), considerando que os erros são ortogonalizados pela decomposição de Cholesky para a estimação do VEC, isto implica que o ordenamento das variáveis torna-se relevante para a análise da função impulso-resposta e da decomposição da variância. Para tanto, o teste de Wald para exogeneidade em bloco (e causalidade de Granger) permite 
afirmar a precedência temporal das variáveis consideradas no modelo. Os resultados estão apresentados na Tabela 6 .

Esse teste é uma alternativa para ordenar as variáveis das "mais exógenas" - afetadas contemporaneamente apenas pelo seu próprio choque estrutural - para as variáveis "mais endógenas" - afetadas contemporaneamente por todos os choques. A partir da estatística Qui-Quadrado, ordenam-se as variáveis das mais exógenas (menores valores da estatística) para as mais endógenas (maiores valores da estatística). De acordo com esse procedimento, tem-se a seguinte ordenação estatisticamente consistente: Fluxo de Capitais, IOF na Saída, Taxa Selic \& IOF na Entrada. Portanto, a medida de controles de capitais na entrada é a variável mais endógena. Este resultado confirma a hipótese de endogeneidade dos controles de capitais no Brasil lançada pioneiramente por Cardoso e Goldfajn (1998). Adicionalmente, demonstrou-se que o IOF na saída também respondia contemporaneamente aos movimentos de capitais.

Tabela 6 - Teste de Wald para Exogeneidade em Bloco

\begin{tabular}{lccc}
\hline Dependente variável & $\chi^{2}$ & $d f$ & Prob (total) \\
\hline IOFINF & 13.62494 & 1 & 0.0035 \\
IOFOUTF & 7.036382 & 1 & 0.0707 \\
KCP & 3.752368 & 1 & 0.2895 \\
TXSELIC & 11.80826 & 1 & 0.0081 \\
\hline
\end{tabular}

Fonte: Elaboração própria a partir da saída do Eviews 4.1.

Obs.: Amostra: 1995:01 1999:12. Observações Incluídas: 59.

Para analisar os resultados do modelo VEC, é comum fazê-lo por meio da função de impulso-resposta e da decomposição da variância. Dada a periodicidade mensal dos dados, utilizou-se, para as análises, um período de 12 meses após a ocorrência dos choques. A função de impulso-resposta é utilizada para fazer uma análise da sensibilidade de determinadas variáveis a certos choques, sendo útil principalmente para conhecer a direção e o tempo de reação das respostas aos impulsos (choques) de um desvio padrão sobre os valores contemporâneos e futuros das variáveis endógenas do sistema. Por fim, observe que a metodologia VAR é particularmente interessante para o exercício realizado neste trabalho, por permitir definir ad hoc o IOF como a variável mais exógena do modelo e, portanto, testar a hipótese de que os controles de capitais, nesse caso, seriam relativamente mais eficazes. Isto posto, as respostas do sistema aos choques estão apresentadas nas Figuras 2, 3 e 4.

Com relação à função impulso-resposta com controles de capitais na entrada e na saída endógenos (Figura 2), o modelo estimado validou a hipótese de endogenida- 
de dos controles de capitais adotados no Brasil, mas rejeitou a hipótese de que os mesmos foram ineficientes, principalmente no caso dos controles sobre a entrada (IOFINF). ${ }^{11}$ Este fato pode ser observado a partir da resposta dos movimentos de capitais de curto prazo a um choque nos controles de capitais na entrada, notado a partir do efeito positivo desse choque no volume positivo desses capitais de curto prazo no período subsequente. Entretanto, os controles de capitais não eliminaram totalmente os impactos dos fluxos de capitais sobre a taxa de juros. Ademais, a resposta dos fluxos de capitais a um choque nesta mesma variável sugere a presença de "comportamento de manada" e de "profecias autorrealizáveis", captados pela inércia dos fluxos de capitais. Este resultado de fato indica algum grau de ineficiência dos controles de capitais endógenos, já que não foram capazes de guiar totalmente as expectativas dos capitais de curto prazo naquele momento. Por fim, os efeitos de um choque do IOFOUTF e do IOFINF sobre os capitais de curto prazo não são revertidos nos 12 meses subsequentes, ou seja, são permanentes.

A decomposição da variância mostra a importância de uma determinada variável $x$ quando se observa o erro de previsão na outra variável $y$. A decomposição da variância dos erros de previsão é uma ferramenta útil por mostrar a evolução do comportamento dinâmico apresentado pelas variáveis em consideração $n$ períodos à frente.

Os resultados da decomposição da variância do fluxo de capitais, no caso de controles de capitais na entrada e na saída endógenos, estão apresentados na Tabela 7. Estes foram obtidos a partir de uma simulação de Monte Carlo com 1.000 repetições. Isto posto, é possível identificar os efeitos dinâmicos dos controles endógenos. ${ }^{12} \mathrm{~A}$ decomposição da variância, para 12 meses após o choque, mostra que a inércia dos choques dos fluxos de capitais sobre a própria variável (comportamento de manada e profecias autorrealizáveis) é elevada: 66,6\%. Constata-se, também, que os principais determinantes do fluxo de capitais no Brasil são a própria variável KCP (66\%), a taxa básica de juros (18\%) e, em menor grau, o imposto sobre operações financeiras na entrada (15\%). Os controles de capitais na saída (IOFOUTF) apresentaram efeito desprezível sobe os fluxos de capitais.

Portanto, os resultados da função impulso-resposta e da decomposição da variância do fluxo de capitais, quando os controles de capitais na entrada e na saída são endógenos, indicam que tais controles endógenos na entrada apresentaram algum grau de eficiência, embora não fossem totalmente eficazes. Além disso, os contro-

11 Para a estimação da função impulso-resposta, a ordenação das variáveis se deu da mais exógena para a mais endógena, conforme sugerido no teste de causalidade de Granger.

12 A ordenação das vaiáveis se deu da mais exógena para a mais endógena, conforme sugerido no teste de causalidade de Granger. 
les sobre a entrada de capitais se mostraram mais eficientes vis-à-vis aos controles sobre a saída.

Response to Cholesky One S.D. Innovations
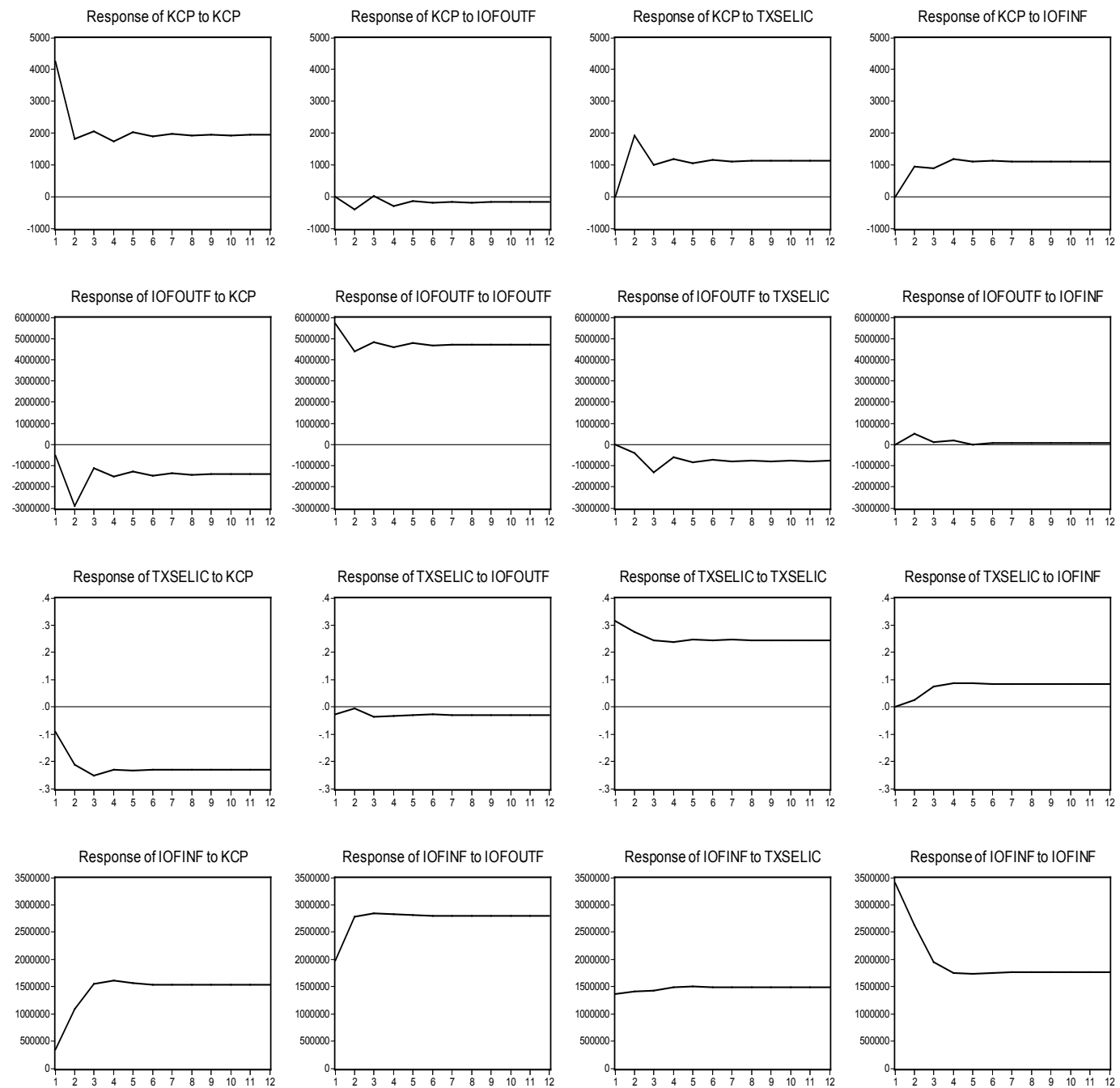

Figura 2 - Função Impulso-Resposta com Controles de Capitais na Entrada e na Saída Endógenos 
Tabela 7 - Decomposição da Variância com Controle de Capitais na Entrada e na Saída Endógenos (\%)

\begin{tabular}{lccccc}
\hline \multirow{5}{*}{ Period } & \multicolumn{5}{c}{ Variance Decomposition of KCP: } \\
\cline { 2 - 6 } & S.E. & KCP & IOFOUTF & TXSELIC & IOFINF \\
\hline 1 & 4247.341 & 100.0000 & 0.000000 & 0.000000 & 0.000000 \\
3 & 5102.558 & 81.78152 & 0.594351 & 14.29393 & 3.330205 \\
4 & 5658.434 & 79.72880 & 0.484682 & 14.65444 & 5.132077 \\
5 & 6152.952 & 75.27422 & 0.657957 & 15.99810 & 8.069723 \\
6 & 6654.423 & 73.53510 & 0.604985 & 16.18371 & 9.676207 \\
7 & 7108.351 & 71.53571 & 0.608418 & 16.85480 & 11.00107 \\
8 & 7537.573 & 70.38795 & 0.584726 & 17.14119 & 11.88614 \\
9 & 7940.716 & 69.28182 & 0.580374 & 17.48028 & 12.65753 \\
10 & 8325.936 & 68.46562 & 0.569854 & 17.70200 & 13.26253 \\
11 & 8693.278 & 67.73556 & 0.564523 & 17.91615 & 13.78378 \\
12 & 9046.134 & 67.14185 & 0.558208 & 18.08244 & 14.21751 \\
\hline
\end{tabular}

Com respeito à função impulso-resposta com controles de capitais na saída exógenos (Figura 3), os efeitos de um choque no IOFOUT, e também no IOFINF, sobre o fluxo de capitais também não são revertidos nos 12 meses subsequentes. O mesmo se observa em relação aos choques no fluxo de capitais sobre a taxa de juros e sobre a própria variável KCP. A inércia nos fluxos de capitais e os efeitos destes sobre a taxa de juros sugerem algum grau de ineficiência desses controles de capitais na saída (exógeno) e controles de capitais na entrada. Constata-se, ainda, que estes últimos respondem aos choques dos controles de capitais na saída, mas a recíproca não é verdadeira.

Os resultados da decomposição da variância do fluxo de capitais, no caso de controles de capitais na saída exógenos, estão apresentados na Tabela 8. A decomposição da variância, para 12 meses após o choque, mostra que a inércia dos choques dos fluxos de capitais sobre a própria variável (comportamento de manada e profecias autorrealizáveis) é elevada: $65,2 \%$. Os resultados encontrados também mostram que os principais determinantes do fluxo de capitais no Brasil são a própria variável $\mathrm{KCP}$, a taxa básica de juros e o imposto sobre operações financeiras na entrada. Os controles de capitais na saída (IOFOUTF) novamente apresentaram efeito desprezível sobre os fluxos de capitais: 1,95\% após 12 meses da ocorrência do choque.

Os resultados da função impulso-resposta e da decomposição da variância, para controles de capitais na saída e na entrada endógenos e para controles exógenos na saída, indicam que o grau de eficiência dos controles de capitais endógenos é muito 
próximo daquele dos controles exógenos. A inércia dos choques dos fluxos de capitais sobre a própria variável é semelhante em ambos os casos de controles na saída endógenos e exógenos, quer na função impulso-resposta, quer na decomposição da variância do fluxo de capitais. O mesmo se verifica com relação aos efeitos dos controles de capitais na saída (exógenos) e controles de capitais na entrada sobre a variável KCP.
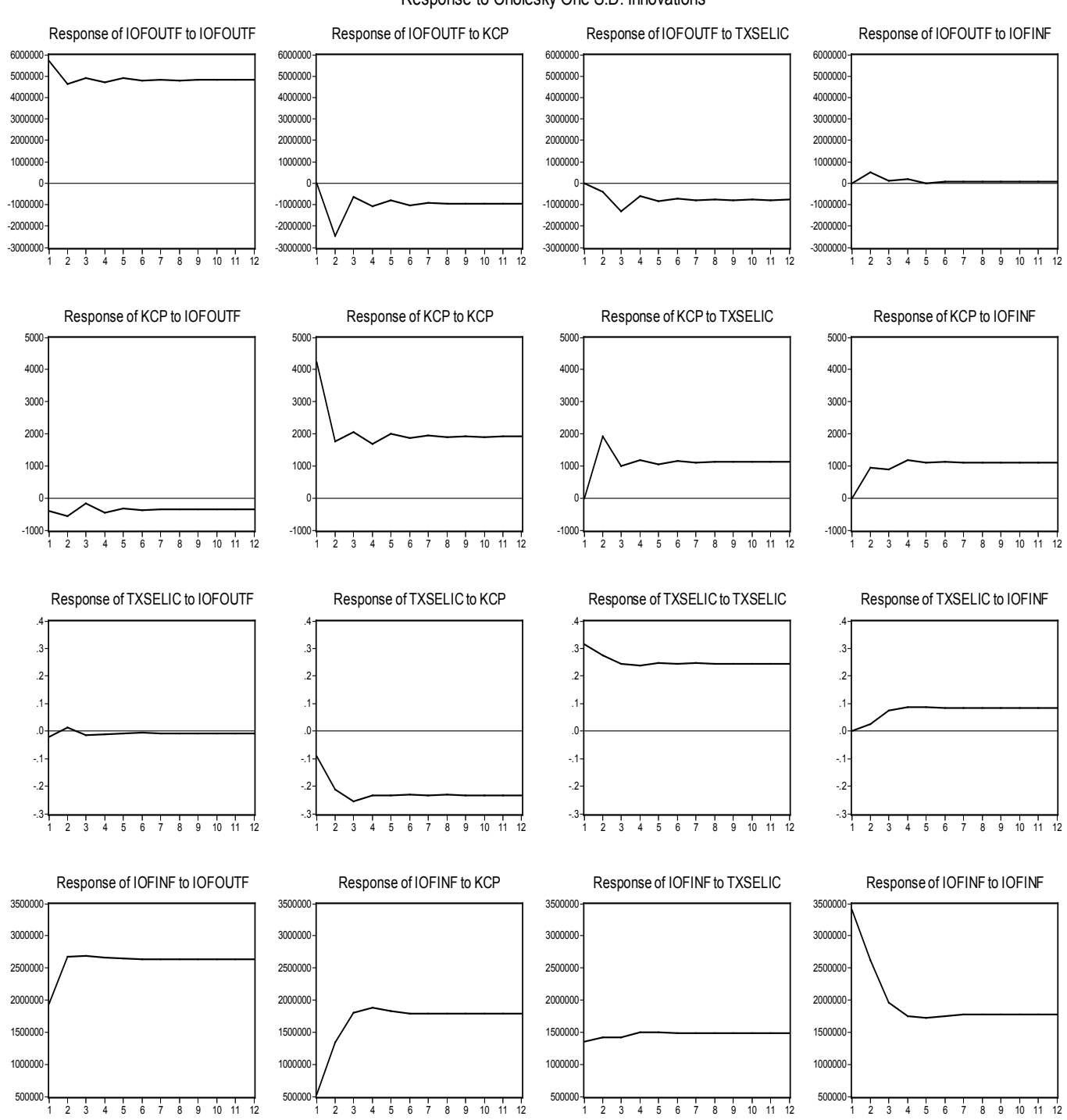

Figura 3 - Função Impulso-Resposta com Controles de Capitais na Saída Exógenos 
Tabela 8 - Decomposição da Variância com Controle de Capitais na Saída Exógenos (\%)

\begin{tabular}{lccccc}
\hline \multirow{5}{*}{ Period } & \multicolumn{5}{c}{ Variance Decomposition of KCP: } \\
\cline { 2 - 6 } & S.E. & IOFOUTF & KCP & TXSELIC & IOFINF \\
\hline 1 & 4247.341 & 0.877045 & 99.12295 & 0.000000 & 0.000000 \\
3 & 5102.558 & 1.814548 & 80.56132 & 14.29393 & 3.330205 \\
4 & 5658.434 & 1.567788 & 78.64570 & 14.65444 & 5.132077 \\
5 & 6152.952 & 1.900751 & 74.03143 & 15.99810 & 8.069723 \\
6 & 6654.423 & 1.864063 & 72.27602 & 16.18371 & 9.676207 \\
7 & 7108.351 & 1.912248 & 70.23188 & 16.85480 & 11.00107 \\
8 & 7537.573 & 1.904589 & 69.06809 & 17.14119 & 11.88614 \\
9 & 7940.716 & 1.924964 & 67.93723 & 17.48028 & 12.65753 \\
10 & 8325.936 & 1.929430 & 67.10604 & 17.70200 & 13.26253 \\
11 & 8693.278 & 1.939227 & 66.36085 & 17.91615 & 13.78378 \\
12 & 9046.134 & 1.944358 & 65.75570 & 18.08244 & 14.21751 \\
\hline
\end{tabular}

Os resultados da função impulso-resposta com controles de capitais na entrada exógenos estão na Figura 4. Os efeitos de choques no IOFOUT e no IOFINF sobre o fluxo de capitais não são revertidos nos 12 meses subsequentes. $\mathrm{O}$ mesmo se observa em relação aos choques no fluxo de capitais sobre a taxa de juros e sobre a própria variável KCP. Ainda que a inércia nos fluxos de capitais e os efeitos destes sobre a taxa de juros permaneçam elevados, se reduziram significativamente neste caso. Note que os efeitos dos controles de capitais sobre os fluxos de capitais aumentaram, tanto na entrada (exógenos) quanto na saída.

Os resultados da decomposição da variância do fluxo de capitais, no caso de controles de capitais na entrada exógenos, estão apresentados na Tabela 9. A decomposição da variância, para 12 meses após o choque, mostra que a inércia dos choques dos fluxos de capitais sobre a própria variável (comportamento de manada e profecias autorrealizáveis) é elevada: $61,7 \%$. Ainda, constata-se que os controles de capitais na entrada exógenos causaram um aumento da participação dos efeitos dos controles sobre os capitais de curto prazo, reduzindo a pressão sobre as taxas básicas de juros. Mais especificamente, o IOFINF, o IOFOUTF e a TXSELIC explicavam, 12 meses após o choque, $22,3 \%, 9,2 \%$ e 6,8\% da variância do fluxo de capitais no Brasil, respectivamente.

Em suma, para o caso de controles de capitais na entrada exógenos, a inércia dos choques dos fluxos de capitais sobre a própria variável reduziu-se um pouco em comparação com os dois casos analisados anteriormente. Do mesmo modo, o 
IOFINF e o IOFOUT aumentaram seu poder de determinação do fluxo de capitais no Brasil em comparação ao caso em que os controles de capitais na entrada e na saída são endógenos. Estes resultados sugerem um maior grau de eficiência de controles de capitais na entrada exógenos vis-à-vis aos controles endógenos.
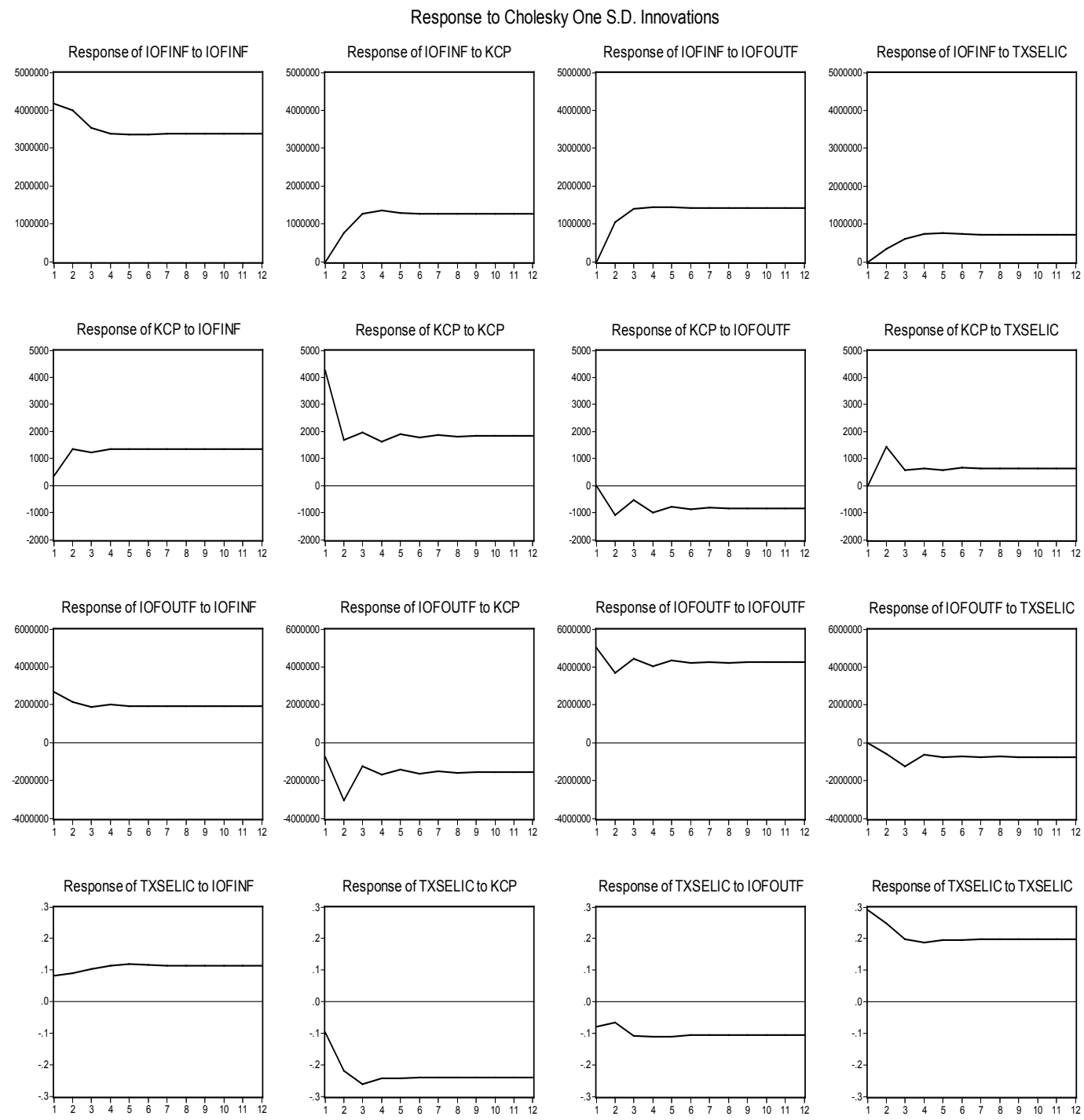

\section{Figura 4 - Função Impulso-Resposta com Controles de Capitais na Entrada Exógenos}


Tabela 9 - Decomposição da Variância com Controle de Capitais na Entrada Exógenos (\%)

\begin{tabular}{lccccc}
\hline & \multicolumn{5}{c}{ Variance Decomposition of KCP: } \\
\cline { 2 - 6 } Period & S.E. & IOFINF & KCP & IOFOUTF & TXSELIC \\
\hline 1 & 4247.341 & 0.676381 & 99.32362 & 0.000000 & 0.000000 \\
2 & 5102.558 & 7.434059 & 79.90052 & 4.633464 & 8.031953 \\
3 & 5658.434 & 10.66683 & 77.02601 & 4.695778 & 7.611379 \\
4 & 6152.952 & 13.78660 & 72.06166 & 6.618937 & 7.532798 \\
5 & 6654.423 & 15.87659 & 69.86423 & 7.093131 & 7.166054 \\
6 & 7108.351 & 17.56179 & 67.54947 & 7.745624 & 7.143123 \\
7 & 7537.573 & 18.75766 & 66.14696 & 8.063237 & 7.032152 \\
8 & 7940.716 & 19.75393 & 64.84280 & 8.415442 & 6.987825 \\
9 & 8325.936 & 20.55248 & 63.86126 & 8.658618 & 6.927646 \\
10 & 8693.278 & 21.23072 & 62.99459 & 8.885393 & 6.889294 \\
11 & 9046.134 & 21.79972 & 62.28443 & 9.065336 & 6.850512 \\
12 & 9385.520 & 22.29074 & 61.66293 & 9.225927 & 6.820400 \\
\hline \multicolumn{5}{c}{ Teste de Causalidade de Granger } \\
\hline \multicolumn{5}{c}{}
\end{tabular}

Pairwise Granger Causality Tests

Sample: 1995M01 1999M12

Lags: 1

\begin{tabular}{lccc}
\hline Null Hypothesis: & Obs & F-Statistic & Probability \\
\hline DKCP does not Granger Cause DIOF & 58 & $3.42007^{\star \star \star}$ & 0.06978 \\
DIOF does not Granger Cause DKCP & & 0.38314 & 0.53849 \\
DTXCAMBIO does not Granger Cause DIOF & 58 & 0.51635 & 0.47545 \\
DIOF does not Granger Cause DTXCAMBIO & & 2.33574 & 0.13217 \\
DTXSELIC does not Granger Cause DIOF & \multirow{2}{*}{58} & 0.03868 & 0.84481 \\
DIOF does not Granger Cause DTXSELIC & & 0.61269 & 0.43713 \\
DTXCAMBIO does not Granger Cause DKCP & \multirow{2}{*}{58} & 0.82680 & 0.36717 \\
DKCP does not Granger Cause DTXCAMBIO & & 1.25446 & 0.26757 \\
DTXSELIC does not Granger Cause DKCP & \multirow{2}{*}{58} & $16.1146^{\star}$ & 0.00018 \\
DKCP does not Granger Cause DTXSELIC & & 1.70349 & 0.19727 \\
DTXSELIC does not Granger Cause DTXCAMBIO & 58 & $5.84365^{\star *}$ & 0.01898 \\
DTXCAMBIO does not Granger Cause DTXSELIC & & $7.37002^{\star}$ & 0.00884 \\
\hline
\end{tabular}

Fonte: Elaboração própria a partir da saída do Eviews 5.

Notas: ${ }^{*}$ Significativo a $1 \% ;{ }^{*}$ Significativo a $5 \% ;{ }^{* * *}$ Significativo a $10 \%$.

Portanto, os resultados das estimações sugerem que tanto os controles de capitais endógenos como também os exógenos apresentaram, no período em análise, algum grau de eficiência. Além disso, pode-se afirmar, com certa confiabilidade, que os controles exógenos são mais eficazes para guiar as expectativas dos agentes, bem 
entendido como comportamento de manada e profecias autorrealizáveis. Por outro lado, não há evidências de que os controles exógenos reverteriam totalmente os efeitos deletérios do fluxo de capitais e a crise cambial em 1999.

Estes resultados indicam a superioridade dos controles de capitais quantitativos sobre aqueles adotados via preços em momentos de grande instabilidade macroeconômica, como aquele observado no final da década de 1990 na economia brasileira. E mais, este resultado é compatível com as hipóteses de comportamento Minskyano do sistema financeiro internacional e de classificação do Brasil na categoria especulativa ou ponzi pelos mercados financeiros mundiais - em períodos de otimismo e expansão do sistema financeiro internacional, o influxo de capitais cresce em todas as economias, mas, durante a reversão cíclica dos mercados financeiros externos, o racionamento de crédito e a fuga de capitais são mais intensos para as economias especulativas e ponzi. Nestes períodos, apenas controles de capitais quantitativos seriam eficientes para impedir uma crise cambial.

Observe ainda que, nos momentos de crise, após 12 meses, apenas 18,2\% (nos casos de controles endógenos sobre a entrada e a saída e de controle sobre a saída exógeno) ou $6,8 \%$ (controle sobre a entrada exógeno) do movimento desses capitais é controlado pela taxa básica de juros (Tabelas 7, 8 e 9). Portanto, estes resultados reforçam a tese de que os custos de um aumento dessa taxa nos períodos de instabilidade macroeconômica são bem maiores que os potenciais benefícios obtidos de uma reversão da crise a partir da política monetária contracionista.

Adicionalmente, os resultados sugerem que a taxa de juros e os controles sobre entrada e saída de capitais foram usados no período em análise como instrumentos substitutos para controlar os fluxos de capitais. Este pode ser observado a partir das Figuras 2, 3 e 4: controles endógenos sobre a entrada e a saída, controle sobre a saída exógeno e controle sobre a entrada exógeno. Mais especificamente, notou-se que um aumento na taxa de juros provoca um aumento no IOFINF e uma redução no IOFOUTF. Este fato é facilmente observado no caso em que os controles de capitais na entrada foram exógenos (utilizados preventivamente). Nesse caso, há uma redução da participação dos efeitos da taxa Selic sobre os fluxos de capitais vis-à-vis ao aumento dos efeitos dos controles de capitais na entrada e na saída. Em outras palavras, o estímulo ao influxo de capitais provocado pelo aumento na Selic era parcialmente compensado com o aumento do IOF sobre a entrada de capitais e uma redução deste imposto sobre a saída de capitais.

Em suma, os resultados das estimações sugerem que os controles de capitais adotados no Brasil, nos anos de 1990, foram endógenos, mas não totalmente ineficientes, como afirmou Schneider (2000). Embora tenham sido colhidas evidências de que 
os controles exógenos de capitais (preventivos) são relativamente mais eficazes, os resultados não permitem afirmar que estes reverteriam totalmente a crise de 1999. Portanto, deveriam ter sido adotadas, naquele momento de crise, medidas via preços mais agressivas ou medidas administrativas, evitando-se políticas desnecessárias e onerosas ao País, como os aumentos estratosféricos da taxa de juros. O efeito final desta política é o aumento desnecessário da vulnerabilidade externa, cujo resultado é precisamente o oposto ao esperado pelas autoridades monetárias.

\section{Considerações Finais}

Um crescente fluxo de capitais - de entrada e de saída - vem ocorrendo na economia brasileira nos anos recentes, fruto da liberalização financeira, iniciada no princípio da década dos 1990, em um contexto de expansão da liquidez em escala mundial. Argumentou-se neste trabalho que economias cujo Sistema Nacional de Inovações (SI) é menos desenvolvido em relação ao SI de outras economias tendem a apresentar de modo recorrente déficits em transações correntes. Como resultado, a vulnerabilidade externa dessas economias torna-se estrutural. Com efeito, essas economias com pequeno desenvolvimento relativo de seus SIs são, então, classificadas como unidade especulativa ou ponzi nos mercados financeiros mundiais, que, por seu turno, teriam um comportamento tipicamente Minskyano, conferindo um racionamento de crédito mais intenso para as economias especulativas e ponzi nos períodos de queda cíclica da liquidez mundial.

Segundo Albuquerque (1999), o SI da economia brasileira e das demais economias em desenvolvimento apresenta pequeno desenvolvimento relativo. Nesta perspectiva, o Brasil se insere no cenário externo como unidade especulativa ou ponzi, devendo ser grande o potencial de desestabilização macroeconômica proporcionado pelos crescentes fluxos de capitais no País, nos últimos anos. A adoção de controles de capitais revela-se, portanto, instrumento importante para uma mudança na estratégia de crescimento da economia, tendo em vista que diminui a vulnerabilidade externa, seleciona os fluxos de capital que se deseja absorver, priorizando os investimentos produtivos ou de maturidade mais longa e confinando os capitais especulativos a volumes administráveis, além de isolar, em algum grau, o País dos choques externos.

Neste trabalho, foram testadas algumas hipóteses sobre a adoção de controle de capitais na economia brasileira nos anos de 1990. Inicialmente, avaliou-se a hipótese de que os controles adotados naquele período foram endógenos, para, em seguida, testar se tais controles, adotados via preços, foram eficazes em reduzir a movimentação de capitais no âmbito da crise cambial de 1999. Ademais, foram testados se 
os controles exógenos seriam mais eficazes do que os endógenos. Para tanto, foi adotado, de modo pioneiro, o método de estimação de Vetores Autorregressivos como uma metodologia alternativa para se testar tais hipóteses. Os resultados observados mostram que os controles de capitais na entrada e na saída, no Brasil, foram de fato endógenos. O trabalho mostrou ainda que os controles de capitais endógenos via preços foram eficazes em reduzir os movimentos de capitais no período analisado, mas esses resultados poderiam ter sido melhores se o grau dessas medidas restritivas fosse mais agressivo. A segunda hipótese de que (naquelas condições) os controles exógenos seriam relativamente melhores não foi rejeitada, embora não seriam suficientemente eficazes para atenuar os movimentos de capitais e, consequentemente, a crise cambial. Para finalizar, as evidências permitem inferir que, nos momentos de grande instabilidade financeira, apenas os controles de capitais quantitativos seriam capazes de efetivamente controlar os capitais de curto prazo em alguns momentos.

Assim, a adoção de controle de capitais pode ser uma das peças fundamentais para uma mudança na estratégia de crescimento de uma determinada economia. Encontrar a melhor estratégia de adoção dos controles de capitais torna-se relevante para os países que desejam reverter essa instabilidade macroeconômica crônica (refletida em amplas e frequentes flutuações nas taxas de câmbio e de juros) e os recorrentes comportamentos do tipo stop and go.

\section{Referências}

ALBUQUERQUE, E. M. Notas sobre a contribuição de Kenneth Arrow para a fundamentação teórica dos sistemas nacionais de inovações. Revista Brasileira de Economia, abr./jun.1996.

. National systems of innovation and non-OECD countries: notes about a rudimentary and tentative typology. Brazilian Journal of political Economy, v. 19, n. 4 (76), Oct.-Dec. 1999.

AMADO, A. M.; RESENDE, M. F. C.; JAYME JR., F. G. Growth cycles in Latin America and developed countries. Belo Horizonte, 2007. (Texto para Discussão do CEDEPLAR, n. 327).

ARESTIS, P.; GLICKMAN, M. Financial crisis in southeast Asia: dispelling illusion the Minskyan way. Cambridge Journal of Economics, v. 26, n. 2, Mar. 2002.

ARIYOSHI, A.; HABEMEIER, K.; LAURENS, B.; TKER-ROBE, I.; CANALESKRILJENKO, J.; KIRILENKO, A. Capital controls: country experiences with their use and liberalization. Washington: IMF, 2000. 
BERNARDES A. T.; ALBUQUERQUE, E. M. Cross-over, thresholds, and interactions between science and technology: lessons for less-developed countries. Research Policy, v. 32, n. 5, p. 865-885, 2003.

CARDOSO, E.; GOLDFAJN, I. Capital flows to Brazil: endogeneity of capital controls. IMF Staff Papers, v.45, n. 1, p. 161-202, 1998.

CARVALHO, F. J. C. Mr. Keynes and the post Keynesians: principles of macroeconomics for a monetary production economy. Aldershot: Edward Elgar, 1992.

CARVALHO, F. J. C.; SICSU, J. Controvésias recentes sobre controles de capitais. In: SICSÚ, J. Emprego, juros e câmbio: finanças globais e desemprego. Rio de Janeiro: Elsevier, 2007.

DOSI, G.; FREEMAN, C.; FABIANI, S. The process of economic development: introducing some stylized facts and theories on technologies, firms and institutions. Industrial and Corporate Change, v. 3, n. 1, 1994.

DOW, S. C. Macroeconomic thought: a methodological approach. Oxford: Blackwell, 1985.

. Money and the economic process. Aldershot: Edward Elgar, 1993.

. International liquidity preference and endogenous credit. In: HARVEY, J. T.; DEPREZ, J. (Ed.). Foundations of international economics: a post Keynesian analysis. London: Routledge, 1999.

EDWARDS, S. Capital mobility and performance: are emerging economies different? National Bureau of Economic Research, 2001. (Working Paper Series, WP $n^{\circ}$ 8076).

EDWARDS, S.; GREGORIO, J.; VALDÉS, R. O. Controls on capital inflows: do they work? Journal of Development Economics, v. 63, n. 1, p. 59-83(25), Oct. 2000.

ENDERS, W. Applied econometric time series. Nova York: John Wiley \& Sons, 1995.

FAGERBERG, J. Technology and international differences in growth rates. Journal of Economic Literature, v. 32, Sep. 1994.

FAJNZYLBER, R. F. La industrializacion trunca de América Latina. México: Nueva Imagem, 1983.

FFRENCH-DAVIS, R. Financial crises and national policy issues: an overview. In: FFRENCH-DAVIS, R.; GRIFFITH-JONES, S. (Org.). From capital surges to drought: seeking stability for emerging economies. New York: Palgrave Macmillan, 2003.

FFRENCH-DAVIS, R.; OCAMPO, J. A. The globalization of financial volatility. In: FFRENCH-DAVIS, R. (Org.). Financial crises in successful emerging economies. Washington, DC: ECLAC/Bookings Institution, 2001. 
FFRENCH-DAVIS, R.; VILLAR, L. Capital account regulations in Chile and Colombia. Santiago de Chile: ECLAC, 2003. Disponível em: <http://www.g24. org/rfrengva.pdf > . Acesso em: 12 mar. 2004.

FREEMAN, C. The National System of Innovation in historical perspective. Revista Brasileira de Inovação, v. 3, n. 1, Jan./June 2004.

GARCIA, M. G. P.; BARCINSKI, A. Capital inflows to Brazil in the nineties: macroeconomics aspects and the efectiveness of capital controls. Rio de Janeiro: PUCRIO/Departamento de Economia, 1996. (Texto para Discussão n. 357).

GARCIA, M. G. P.; VALPASSOS, M. V. F. Capital flows, capital controls and currency crisis: the case of Brazil in the nineties. Rio de Janeiro: PUC-RIO/Departamento de Economia, 1998. (Texto para Discussão n. 389).

GRANGER, C. W. J. Investigating causal relations by econometric models and crossspectral methods. Econometrica, v. 37, p. 424-438, 1969.

IPEADATA. Rio de Janeiro: IPEA. Disponível em: < http://www.ipeadata.gov.br> . Acesso em: 20 mar. 2009.

JAYME JR., F. G. Balance-of-payments-constrained economic growth in Brazil. Revista de Economia Política, v. 23, n. 1 (89), Jan.-Mar. 2003.

KWIATKOWSKI, D.; PHILLIPS, P. C. B.; SCHMIDT, P.; SHIN, Y. Testing the null hypothesis of stationarity against the alternative of a unit root: how sure are we that economic time series have a unit root? Journal of Econometrics, 54, p.159-178, 1992

LEMTe - Laboratório de Estudos sobre Moeda e Território do Cedeplar/UFMG.

MCCOMBIE, J.; THIRLWALL, A. Economic growth and the balance of payments constraint. New York: St. Martin's Press, 1994.

MADDALA, G. S.; KIM, I. M. Unit roots, cointegration and structural change. Cambridge (UK): Cambridge University Press, 1998.

MATSUMOTO, K. Efeitos reais da transmissão de política monetária: comparação empírica entre Brasil e Argentina. Dissertação (Mestrado) - FGV-RJ, Rio de Janeiro, 2000.

MENDONÇA, H. F. Metas para inflação e variáveis macroeconômicas: uma avaliação empírica. In: ENCONTRO NACIONAL DE ECONOMIA - ANPEC, 33, 2005, Natal. Anais... Natal: ANPEC, 2005.

MINSKY, H. P. Stabilizing an unstable economy. New Haven: Yale University Press, 1986.

NEELY, C. J. An introduction to capital controls. St. Louis Federal Reserve Bank Review, v. 81, n. 6, Nov.-Dec. 1999.

NELSON, R. R. Economic development from the perspective of evolutionary economic theory. Belo Horizonte: CEDEPLAR, 2005. (Seminários Internos/ CEDEPLAR). 
ONO, F. H.; SILVA, G. J. C.; OREIRO, J. L. C.; PAULA, L. F. R. Conversibilidade da Conta de Capitais e Seus Desdobramentos: evidências a partir da experiência recente da economia brasileira e mundial. In: ENCONTRO DE ECONOMIA DA REGIÃO SUL, VII. 2004 In: Anais.... Maringá: Universidade Estadual de Maringá, 2004. v. 1. p. 197-218.

ONO, F. H.; SILVA, G. J. C.; OREIRO, J. L. C.; PAULA, L. F. R. Conversibilidade da conta de capital, taxa de juros e crescimento econômico: uma avaliação empírica da proposta de plena conversibilidade do real. Revista de Economia Contemporânea scr, v. 1, n. 9, p. 231-261, 2005.

OREIRO, J. L. Autonomia de política econômica, fragilidade externa e equilíbrio do balanço de pagamentos: a teoria econômica dos controles de capitais. Revista Economia e Sociedade, v. 13, n. 2 (23), p. 1-22, jul./dez. 2004.

OREIRO, J. L.; PAULA, L. F.; SILVA, G. J. C. Por uma moeda parcialmente conversível: uma crítica a Arida e Bacha. Revista de Economia Política, v. 24, n. 2, 2004.

PAULA, L. F. Controle de capitais: lições para o Brasil. In: BENECKE, D. W.; NASCIMENTO, R. (Org.). Opções de política econômica para o Brasil. Rio de Janeiro: Fundação Konrad Adenauer, 2003.

PAULA, L. F. R.; ALVES JÚNIOR, A. J. External financial fragility and the 19981999 Brazilian currency crisis. Journal of Post Keynesian Economics, v. 22, n. 4, 2000.

PAULA, L. F.; OREIRO, J. L.; SILVA, G. Fluxos e controle de capitais no Brasil: avaliação e proposta de política. In: SICSÚ, J.; OREIRO, J. L.; PAULA, L. F. Agenda Brasil: políticas econômicas para o crescimento com estabilidade de preços. São Paulo: Manole, 2003.

PLIHON, D. A ascensão das finanças especulativas. Economia e Sociedade, Campinas, v. 5, p. 61-78, dez. 1995.

PREBISCH, R. Problemas teóricos e práticos do crescimento econômico. In: BIELSCHOWSKY, R. (Org.). Cinquenta anos de pensamento na CEPAL. Rio de Janeiro: Record, 2000.

RAMASWAMY, R.; SLØK, T. The real effects of monetary policy in the European union: what are the differences? IMF Staff Papers, v. 45, n. 2, 1998.

RESENDE, M. F. C. O padrão dos ciclos de crescimento da economia brasileira: 1947-2003. Economia e Sociedade, Campinas, v. 14, n. 1 (24), p. 25-55, jan.jun. 2005.

RESENDE, M. F. C.; AMADO, A. M. Liquidez internacional e ciclo reflexo: algumas observações para a América Latina. Revista de Economia Política, v. 27, n. 1, jan.-mar. 2007.

RESENDE, M. F. C.; TORRES, D. A. R. National innovation system, competitiveness and economic growth. Belo Horizonte: CEDEPLAR, 2008. Disponível 
em: < http://www.cedeplar.ufmg.br>. (Texto para Discussão-CEDEPLAR, n. 325).

SCHNEIDER, B. Issues in capital account convertibility in developing countries. . London: Overseas Development Institute, 2000. Disponível em: < http://www. odi.org.uk/speeches/schneider.pdf>. Acesso em: 20 abril 2004.

SIMS, C. Macroeconomics and reality. Econometrica, v. 48, n. 1, p. 1-48, 1980.

SOIHET, E. Índice de controle de capitais: uma análise de legislação e dos determinantes ao fluxo de capital no Brasil no período de 1990-2000. Dissertação (Mestrado) - Escola de Pós-Graduação em Economia, FGV, Rio de Janeiro, 2002. 